\title{
Crow damage to almonds increasing; no foolproof solution in sight
}

\author{
Janine Hasey $\square \quad$ Terrell P. Salmon
}

\section{Of all birds causing damage to almonds in Sutter and Yuba counties, crows cause the most, according to a survey of grow- ers. Growers also reported they are willing to spend an average of \$24 an acre to reduce damage by $50 \%$ within their orchards - far less than the potential value of nuts lost.}

Among California crops damaged by birds, nut crops such as almonds, pistachios and walnuts are particularly hard hit. Although information on natural losses is limited, bird losses to California pistachio crops reportedly exceed $\$ 1.8$ million per year. The most damage occurs when birds feed on nuts or knock them to the ground when they land in trees.

Within Northern California's Sutter and Yuba counties, almonds are grown on approximately 6,305 acres. For several years, growers have been reporting that birds, particularly crows, are causing extensive crop losses. Because data were not available to document this issue, we surveyed growers in October 1987 for their opinions about bird damage and, to a limited extent, on the effectiveness of their control measures.

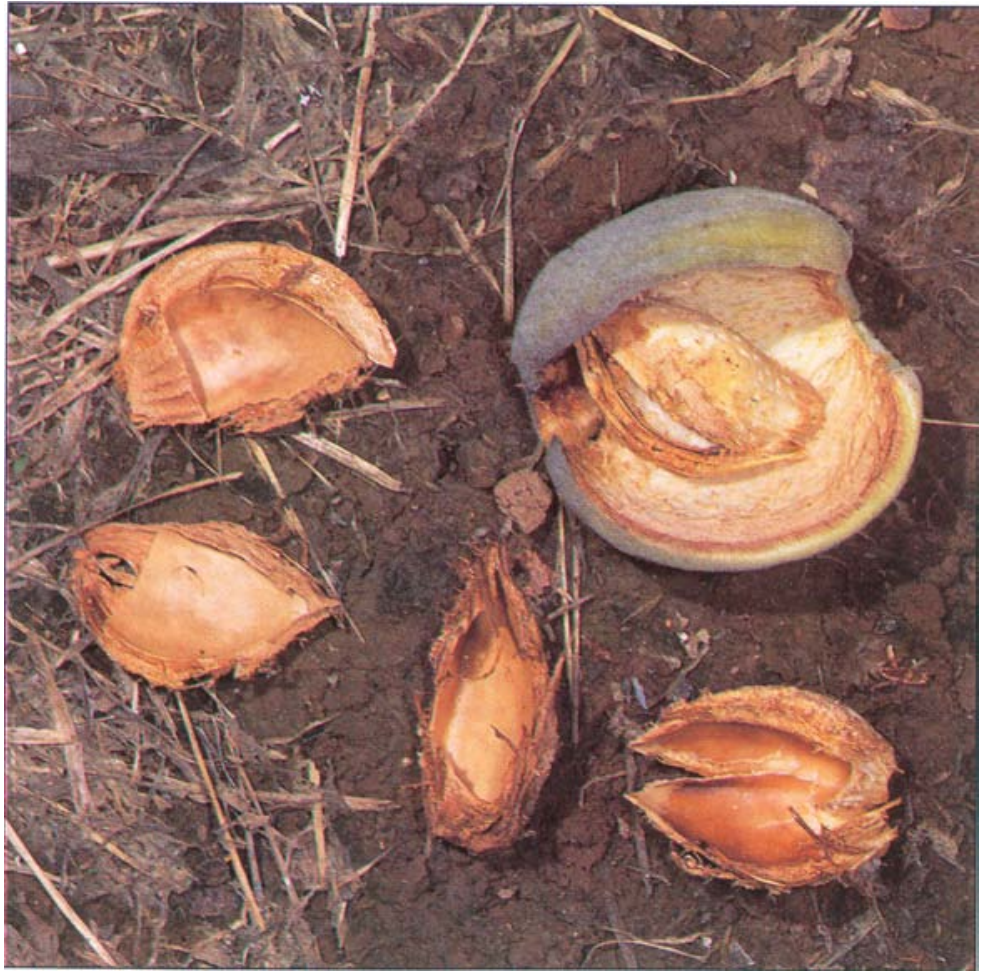

Almonds damaged by crows. most of the area's commercial almond growers. The survey asked growers to identify the bird species involved, the extent and degree of damage, the control methods used and the perceived effectiveness of those methods.

The first portion of the survey, identifying the birds causing problems, looked also at the tree crops involved. Although the survey concentrated on almonds, information on other crops was solicited to give us a better understanding of the bird population and potential problems in both counties.
One week after the deadline for returning the survey, reminder cards were sent to those growers who had not returned the survey. Three months later, we randomly contacted by telephone 49 growers on the original mailing list to check for any nonrespondent bias. All telephone contacts who did not return the survey were asked to fill it out, with us assisting them over the phone.

To follow up on the initial survey, 11 growers who had consistently reported bird damage in previous years were interviewed in July 1988 to determine whether they had seen any increases or decreases in crow populations in their orchards. In many of these orchards, damage to nuts had also been reported to, and subsequently observed by, the local UC farm advisor (senior author).

\section{Results}

Of the 622 surveys mailed, 145 were completed, a return rate of $23.3 \%$. This return rate is similar to that of other surveys we have conducted on wildlife damage to crops. During the nonrespondent check, 18 contacts $(36.7 \%)$ indicated they had already returned the survey. Twenty nonrespondents either were no longer farming $(38.7 \%)$ or had perceived no bird problems $(25.8 \%)$. Only about one-third of the nonrespondents $(35.5 \%)$ had some bird damage. This demonstrates a nonrespondent bias where

\section{Methods}

The survey we developed was mailed to 622 commercial tree crop growers in Sutter and Yuba counties, including out bird problems (or who the survey. We concluded that the crop loss data reported represent a liberal estimate of bird damage in almonds in growers without bird problems (or who
were no longer farming) failed to return 
Sutter and Yuba counties, although the degree of damage to the entire local industry cannot be determined.

\section{Scope of the problem}

Table 1 lists the tree crops for which growers reported damage by birds and the bird species identified. Except for almonds, we do not have information on the number of responding growers who grew each of the specific tree crops listed. Other crops damaged by birds were pecans, wild rice, melons, grapes, vine seed crops, sugar beets, pastures and apples. Growers reported the American crow (Corvus brachyrhynchos) as the most frequent pest bird of almonds, as well as other crops, followed by the yellow-billed magpie (Pica nuttalli). The Brewer's blackbird (Euphagus cyanocephalus) and scrub jay (Aphelocoma coerulescens) were also reported as commonly causing problems in almond orchards.

To refine the scope of problems crows cause in almonds, we concentrated on their behavior and occurrence in almond orchards. Of the surveys returned, 64 were from commercial almond growers. Of these, $97 \%$ reported crows in their orchard. Crows occur in almond orchards throughout the year, with concentrations during the time when nuts are maturing and during pre- and postharvest. Even during winter when trees are dormant, $10 \%$ of the growers found crows in their orchards. These crows eat mummy nuts, thereby reducing navel orangeworm, a serious pest of almonds. Flock sizes in the orchard vary; however, most growers indicated that groups of six or more birds were found in the orchard. In most cases, birds in groups of 26 and more were common.

Decisions about investing in birdcontrol equipment or programs require information about the potential damage these birds can cause. Growers were asked specifically about crop losses from

\begin{tabular}{|c|c|c|c|c|}
\hline \multirow[b]{2}{*}{ Crop } & \multicolumn{4}{|c|}{ Birds causing damage } \\
\hline & Crow & Blackbird & Magpie & Other \\
\hline & \multicolumn{4}{|c|}{ 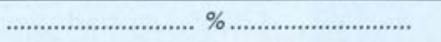 } \\
\hline Almond & 35 & 10 & 13 & 12 \\
\hline Walnut† & 56 & 6 & 17 & 8 \\
\hline Prune & 13 & 8 & 4 & 1 \\
\hline Peach & 8 & 5 & 4 & 8 \\
\hline Pear & 2 & $<1$ & 1 & 1 \\
\hline Kiwifruit & $<1$ & 0 & 0 & 1 \\
\hline Cherry & 4 & 1 & 3 & 5 \\
\hline
\end{tabular}

"Survey conducted in 1987 among growers in Sutter and Yuba counties.

†While many growers report seeing bird damage on walnut, it usually is not as severe or economically significant as the damage reported on almond.

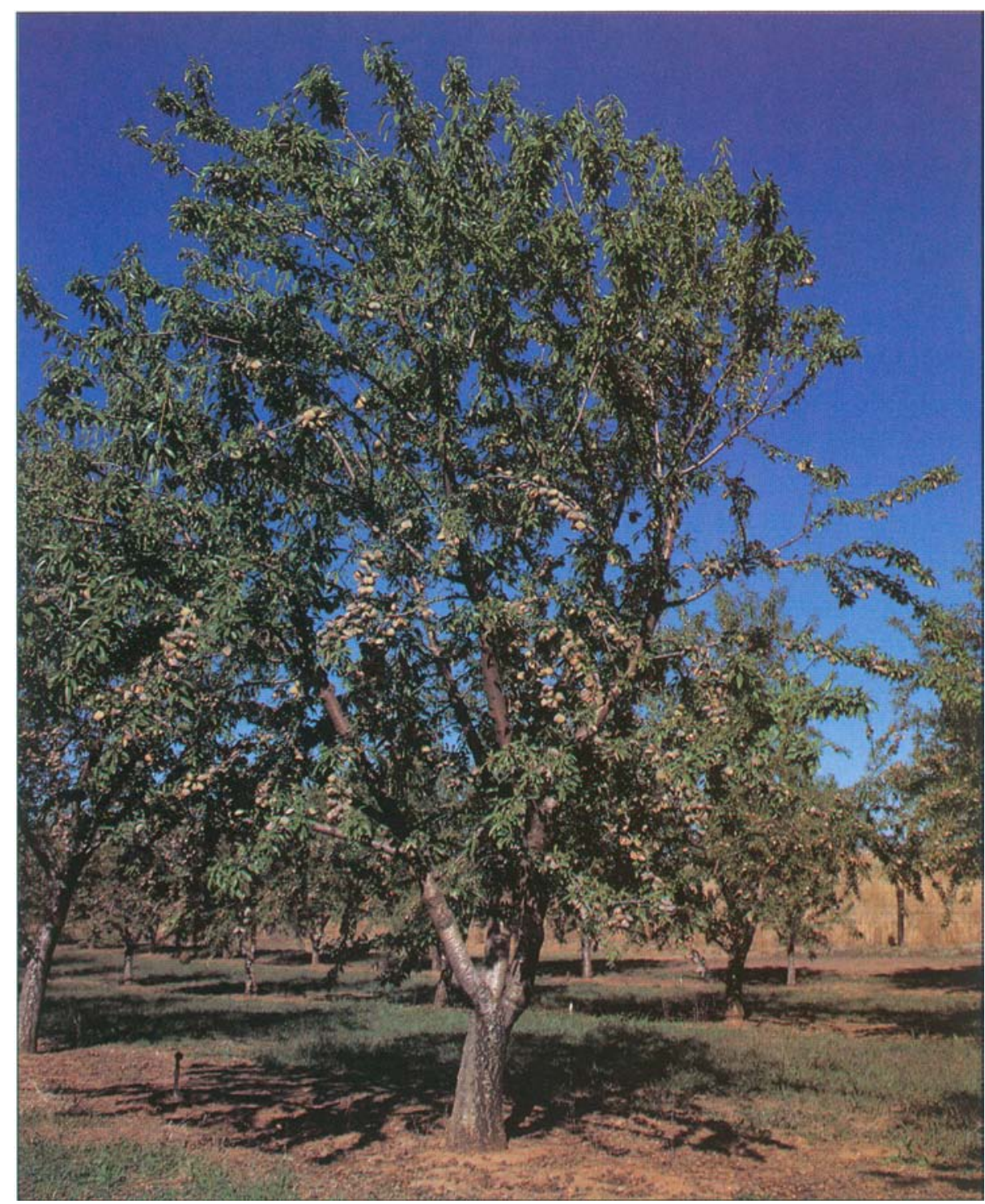

\section{Upper crop of almonds stripped off by birds.}

crows feeding in their orchards. Most growers $(90 \%)$ reported bird damage in their almond orchards. Of growers reporting damage, $98 \%$ felt damage is increasing. No grower found crow damage declining. Asked why crow damage was up, most growers (59\%) said that crow numbers were increasing and so damage was increasing; changes in the surrounding habitat (unspecified) also seemed to be causing the increase in crows, they said.

Of the 11 almond growers interviewed the following summer, all but one reported crop damage by crows. Four said they had more damage than in previous years, four thought damage was about the same and two felt there had been less bird damage.

Knowledge about the feeding behavior of crows in the orchard is necessary to evaluate their damage and to apply control programs to specific areas where crows are pests. Growers reported both concentrated and dispersed crow dam- age throughout their orchards at about equal rates. It appears that because damage can be, and often is, distributed throughout an entire orchard, damage prevention has to be orchardwide.

Evaluating damage by crows and other birds in almond orchards is difficult. Most growers simply estimate the entire loss for the orchard. For growers experienced with bird damage and production within their orchards, such estimates can help address the cost/benefits of various control programs. However, because bird damage tends to be sporadic, many growers new to almond production or to bird problems may find it hard to estimate overall losses.

To fully calculate the estimated loss in an orchard, we asked growers to describe the yield loss from one tree with average crow damage. Growers estimated that the yield of an average tree damaged by crows was reduced 20 to $25 \%$. They also indicated that about $15 \%$ of the trees in their orchards were dam- 
aged by crows. From these estimates, we calculated a 3 to $4 \%$ loss in production, about 40 pounds per acre, for those returning the survey. In estimating overal loss, average losses in the range of 1 to $5 \%$ and 6 to $10 \%$ were reported by $28 \%$ and $26 \%$ of the growers, respectively; $24 \%$ of the growers indicated losses in the range of 11 to $50 \%$.

\section{Control methods used}

Growers were asked to rate the methods used to control bird pests. Of all of the measures used to frighten or disperse birds, shooting was the most common, followed by gas cannons (propane exploder), hawk kites (kites that look like predatory birds) and electronic noise makers (AV-Alarm). Shooting and gas cannons were rated by $47 \%$ and $40 \%$ of the growers, respectively, as giving slight control; $25 \%$ and $32 \%$, respectively, said shooting and gas cannons moderately controlled crows. Trapping, netting, recorded bird calls and bird bombs were also used. Asked how much they would be willing to spend to reduce crow damage in their orchards by $50 \%$, growers gave responses ranging from $\$ 0$ to $\$ 100$ per acre, with an average of $\$ 24.46$ per acre.

Asked to list environmental conditions near their orchards that they felt contributed to crow problems, growers commonly listed tall trees and water sources as contributing to specific bird problems. In addition, wooded areas, brushlands and power lines were associated with crow problems.

\section{Conclusion}

Among birds, crows reportedly cause the most damage to almonds and other crops throughout Sutter and Yuba counties. Magpies are the second most detrimental bird species reported, closely followed by blackbirds, starlings and scrub jays. Bird damage is believed to be getting worse each year in some orchards, as a result of increased bird numbers.

Control methods vary, depending on their cost effectiveness. To reduce damage by $50 \%$ in their orchards, almond growers are willing to spend an average of $\$ 24.46$ per acre, far less than the potential value of nuts lost to such damage. The most effective deterrent appears to be shooting, followed by gas cannons (propane exploders). No control apparently gives excellent results consistently and no improved alternative has been found.

J. Hasey is Farm Advisor, Sutter-Yuba counties, and T. P. Salmon is Extension Wildlife Specialist, Department of Wildlife and Fisheries Biology, UC Davis.

\title{
Berber orchardgrass tested as cover crop in commercial vineyard
}

\author{
James A. Wolpert $\square \quad$ Phil A. Phillips $\square \quad$ R. K. Striegler \\ Michael V. McKenry $\square$ John H. Foott
}

\section{A Berber orchardgrass cover crop reduced the growth and yield of Cabernet Sauvignon grapevines. Some nematode and arthropod pest populations were signiff- cantly lower in the cover crop plots; one was higher.}

Increasing interest in the use of cover crops in commercial viticulture prompted a field experiment which demonstrated that a Berber orchardgrass cover crop can severely reduce grapevine growth and yield, alter vine water status and influence pest population.

The recent attention to vineyard cover crops can be attributed to their ability to moderate vine growth under high fertility conditions, to reduce erosion, to improve soil tilth and to aid integrated pest management goals by harboring beneficial arthropod predators or parasites. Before cover crop use can be recommended, however, the competition of cover crops with vines under various cultural practices needs study as does the possibility of potential encouragement of injurious pests.

\section{Trial conditions}

The trial area was a 26.7-acre, mature, own-rooted Cabernet Sauvignon vineyard located about 8 miles southeast of Santa Maria in Santa Barbara County. The vineyard was planted on a 7-foot by 12-foot spacing (vine by row). In late 1987 , Berber orchardgrass was sown in the inter-row middles, in four blocks of 12 middles each; a 2-foot strip under the vines was kept clean with herbicide applications. Treatment blocks alternated with four 12-middle blocks of clean cultivation that were maintained by regular discing and dormant-season herbicide applications in a 2-foot strip under the vine rows. Wide plots were designed to restrict, as much as possible, pest migration from one treatment to another.

This production area is noted for relatively low winter rainfall and vines are irrigated during the growing season by overhead sprinkler. The total water (winter rainfall plus irrigation) received in the control plots was 18.8 inches $(13.0$ plus 5.8 ) in $1988,19.0$ inches $(10.4$ plus 8.6 ) in 1989 and 17.1 inches (9.1 plus 8.0) in 1990. The Berber cover plots received identical irrigation applications, except in 1990 when they received 3 inches of additional irrigation, bringing the total water received in cover treatments to 20.1 inches. No fertilizer was applied to the experimental area, except in 1990 when the Berber plots received 45 pounds of actual nitrogen as UAN-32 (urea and ammonium nitrate.)

Vines were trained to a two-wire vertical trellis with wires located at about 42 inches and 60 inches above the soil. Vines were cordon-trained on the lower wire and pruned to a combination of 10 to 12 two-bud spurs and four 12- to 15bud canes. Canes were wrapped and tied to the upper wire. At the start of the experiment, vines were considered excessively vigorous and were yielding low amounts of poor quality fruit. The cover crop was being investigated for its potential to reduce excessive vine vigor and thus improve bud fruitfulness and vine yield.

In one of the three center rows of each 12-row block, 10 contiguous vines were selected for uniformity of growth and were marked as data vines for the course of the experiment. Data were recorded, beginning with the harvest in 1988 and continuing for 2 years. Grapevines were individually hand-harvested, clusters were counted and per-vine weights recorded. Before harvest, a single 100-berry sample per treatment replicate was taken and weighed to determine average berry weight. The sample was crushed and juice was analyzed for sugar concentration ( $\left.{ }^{\circ} \mathrm{Brix}\right)$, titratable acidity (TA) and $\mathrm{pH}$. During the subsequent dormant season, vines were pruned and the weight of cane prunings recorded.

During the 1990 growing season, monthly measurements of vine water 